\title{
A natural nano ozonated oil composition for high blood pressure cure
}

\begin{abstract}
The present patent-pending invention relates to a topical pharmaceutical nano ozonated composition for high blood pressure. The composition for treating this problem preferably formed of a natural oil mix, basil oil, coriander oil, ozonated olive oil and ozonated lemon balm (Mellissa) oil. In particular the composition is topically applied on neck and hands. Observed results showed excellent results for all ages of men and women with no adverse or side effects.
\end{abstract}

Keywords: hypertension, hypertensive, high blood pressure; nano, ozonated and vasodilator
Volume 5 Issue 6 - 2018

\author{
Awad Mansour,' Ammar Mansour² \\ 'University of Akron, USA \\ ${ }^{2}$ Essraa Hospital, Jordan
}

Correspondence: Awad Mansour, University of Akron, $\mathrm{OH}$, USA, Tel 96279-5540635, Email profmensour@gmail.com

Received: October I, 2018 | Published: November 19, 2018

\section{Introduction}

High blood pressure is a common condition may eventually lead to health problems. Hypertensive patient can have high blood pressure (hypertension) for years without any symptoms. Even without symptoms, that is why it is called the silent killer. Uncontrolled high blood pressure increases your risk of serious heart problems.

\section{Description of the invention}

The number of people living with high blood pressure worldwide has doubled over the last 40 years. ${ }^{1}$

High blood pressure is the leading cause of heart disease and stroke, killing around 7.5 million people worldwide every year.

Current patient's number is over 1.1 billion.

Though different types of high blood pressure medications are available everywhere in the world patients still suffer of an absence of real safe medications to solve this serious problem.

Side Effects of High Blood Pressure Medications. ${ }^{2}$

Common side effects of high blood pressure medicines include:

a. Cough

b. Diarrhea or constipation

c. Dizziness or light-headedness

d. Erection problems

e. Feeling nervous

f. Feeling tired, weak, drowsy, or a lack of energy

g. Headache

h. Nausea or vomiting

i. Skin rash

j. Weight loss or gain

Based on the serious critical situation of chemical medications used to treat high blood pressure it is necessary to find a reliable safer alternatives and this is the subject of this paper.
Compositions comprising natural extracts can be used to treat high blood pressure. For example, the present invention relates to compositions, basil oil, coriander oil, ozonated olive oil and ozonated lemon balm (Mellissa) oil. The compositions can produce hypotension effect on hypertensive patients.

\section{Basil oil}

In a recent research paper Rahul Jain et al. ${ }^{3}$ carried out a study on active constituents of basil oil and showed that its volatile contains hypertensive ingredients which make basil oil a fast topical hypertensive agent.

\section{Coriander oil}

Awad Mansour in his book ${ }^{4}$ the 50 Miracle Cures of Coriander showed that coriander is hypertensive, vasodilator \& vasorelaxant. It can also break down fats from the blood, making its passage through the veins smoother. Qaiser Jabeen et al. ${ }^{5}$ performed an in-vitro and in-vivo study using Coriander extract as a hypertension agent and as diuretic and their results indicated that coriander exhibits hypertensive effects.

\section{Ozonated olive oil}

According to the institute's director, urologist Dr. Juan Carlos Ruiz de la Roja ${ }^{6}$ the scientific explanation is very simple. "Olive oil has been shown to have a vasodilator effect due to the liberation of nitric oxide, which improves blood flow overall. The top benefits of ozonated essential oils ozonated oil holds a variety of health benefits, but is most commonly used for conditions of the skin and external body, much as you would use a therapeutic salve or cream. As a massage paste, the ozonide acts as an antioxidant, allowing lactic acid and toxins to be released from the pores of the skin.

Melissa oil has the power to lower blood pressure levels ${ }^{7}$ because of its hypertensive, antihyperlipidemic, ant arrhythmic, neuroprotective and hepatoprotective properties. A 2015 animal study published in Research in Cardiovascular Medicine found that Melissa essential oil is associated with significant electrocardiogram alternations in rats. The electrocardiogram is a test that's used to check for problems with the electrical activity of your heart. 
Another animal study, ${ }^{8}$ conducted in 2016, found that Melissa oil reduces the heart rate of injured rats and increases the heart's resistance to injury. ${ }^{9}$

\section{Maximum bioavailability}

The herbal composition if used as an oral formulation its bioavailability will be poor compared to a topical (external) applications on skin. To give good bioavailability, it was found that this oil with its nano particle size did give maximum bioavailability effect.

\section{Summary of the invention}

The present invention relates to a topical natural formulation for treatment of high blood pressure. The composition is formed of basil oil, coriander oil, ozonated olive oil and ozonated lemon balm (Mellissa) oil.

\section{Results and discussion}

The following results were obtained at the clinic of Dr. B. Khasawneh on random basis:

24 males and females with high blood pressure entered this trial for 3 months only and reduced the dosages of their chemical medications till they rid of all medications.

One of the cases who entered this study 9 years ago is the author of this paper, Prof. Awad Mansour who discovered in 2009 his high blood pressure which was 190/105. Prof. Mansour refused to take any chemical drug and preferred to try this oil mix topically for 3 months only!! And discovered he was cured on permanent basis.

Prof. Mansour measures his blood pressure on monthly basis. His latest measurements at the end of September 2018 are attached.

\section{Safety and toxicity study}

Toxicity study performed at Jordan University of Science and Technology animal house on mice showed that the formulation is free of any adverse effects especially on liver, kidneys, lipid and other body organs.

\section{Conclusion}

This patent-pending natural nano oil mix is expected to help hundreds of millions of hypertensive people who suffer from high blood presser worldwide since it works on a number of mechanisms: enhancing blood circulation; violating blood vessels, and liberating Nitric Oxide. Double blind is still needed to give more reliable results.

\section{Acknowledgements}

Efforts of Dr. B. Khasawneh during the course of this study are highly appreciated.

\section{Conflict of interest}

The author declares no conflict of interest.

\section{References}

1. Billion people worldwide now have high blood pressure. 2017.

2. We're sorry. We can't find the page you requested.

3. Rahul Jain, Mohammed Aqil, Abdul Ahad. Basil Oil is a Promising Skin Penetration Enhancer for transdermal Delivery of Labetolol Hydrochloride. Drug Dev Ind Pharm. 2008;34(4):384-389.

4. Awad Mansour, the 50 Miracle Cures of Coriander. USA; 2011.

5. Jabeen Q, Bashir S, Lyoussi B. Coriander fruit exhibits gut modulatory, blood pressure lowering and diuretic activities. J Ethnopharmacol. 2009;122(1):123-130.

6. Julie Butler. Tomatoes and Olive Oil May Reduce Impotence. 2012.

7. Bounihi A, Hajjaj G, Alnamer R. In Vivo Potential Anti-Inflammatory Activity of Melissa officinalis L. Essential Oil. Adv Pharmacol Sci. 2013;2013:101759.

8. Joukar S, Asadipour H. Evaluation of Melissa officinalis (Lemon Balm) Effects on Heart Electrical System. Res Cardiovasc Med. 2015;4(2):e27013.

9. Joukar S, Asadipour H, Sheibani M. Dabiri-9 The effects of Melissa officinalis (lemon balm) pretreatment on the resistance of the heart to myocardial injury. Pharm Biol. 2016;54(6):1005-1013. 